\title{
On the Techniques of English Fast-reading
}

\author{
Jun Xu \\ English Department of Dezhou University, China \\ Email: xujun56cn@yahoo.com.cn
}

\begin{abstract}
With the deepening reform of English language teaching and English major talents cultivation and the application of new English exam module, English fast-reading plays a more significant role in life, work and learning. This paper points out the significance of English reading, in particular fast-reading, analyzes the problems existing in students' reading competence and proposes approaches and strategies to improve reading competence.
\end{abstract}

Index Terms - English fast-reading, techniques, strategies

\section{THE SIGNIFICANCE OF ENGLISH FAST-READING}

With the coming of the new technology revolution and development of modernization, the world has entered an unprecedented era. Quick pace of life and high efficiency are the distinctive features of the era. To adapt to the current situation, almost all walks of life, governments at all levels have improved their efficiency. Should reading, one of the most important media to convey information and English reading teaching focused on cultivating reading competence improve efficiency? Can they be highly efficient? This is the challenge imposed by the times and reality. UNESCO statistics show that from 1750 to 1950 , the world's population has increased twice, and books by 800 times. Besides, the information from books published between 1950-1970 has totaled that of the past 3000 years. In spite of slight authoritative statistics at hand, it is a fact that with advent of the 21 st century, knowledge has been increasing and updating. It is learned through reality that people's reading speed and competence can hardly keep in pace with the development of informationized society. Gu Xiaoming (1985), a famous expert on sociology and reading science pointed out in his strategies of reading that the backward reading approach has weakened talents cultivation as well as the progress of the whole nation.

Favorable reading competence is of vital importance in the basic stage of university English teaching. The "New Syllabus for University English Teaching" maintains that the objective of university English education is to improve the students' reading, listening, basic writing and speaking competence to acquire more professional information with English as an instrument and further develop their overall English competence. And hence, it is urgent to intensify the training of reading on students.

The reading competence mainly lies in intensive reading and extensive reading. However, English reading speed has been one of the major concerns. Generally, in practical work and life, fast-reading takes up $80 \%-90 \%$ in reading, through which we can read widely to obtain more information and broaden our horizons. In addition, frequent access to materials enlarges vocabulary and grammar, develops reading skills and comprehension capacity and enhances interest in reading. The basic knowledge mainly concerns English professional knowledge. Without certain professional knowledge, hardly can we gain a better understanding about the content.

\section{Problems IN CURRENT ENGLiSh FAST-READING LEARning}

Over recent years, with great development of foreign language teaching methodologies in our country, outdated teaching methods have been eliminated. However, English teaching has left far behind with the current situation. Many teachers are still limited to grammar teaching and ignore training of reading. English words are formed by alphabetic, a set of symbols representing vocal sounds. These symbols convey certain thoughts or ideas. So it's easier for readers to associate printed letters with vocal sounds in disregard of the fact that words are not supposed to utter in reading comprehension. When doing the fast-reading, it is required that students be totally attentive and the classroom quiet, for any sound may distract students. But some students like reading out. The moving of lips affects the speed of scanning. "An efficient reader can catch the meaning at the sight of symbol rather than going through the verbal stage." (Edward,1963, P211). In order to "get focused", some students put fingers under lines and read each single word, in case of any strange words, they should stop and can't understand the whole passage. Some may re-read the whole the sentence or paragraph if new words or phrases come up. Others incline to translate the words and sentences so as to understand the text through Chinese. Still, some students tend to analyze the grammar structure, even if reading a novel, to get the general idea and study each word for its lexical and grammatical usage. These inadequate reading habits hamper students' sufficient time for expanding reading and detain their progress in study. Year on year buried in text books, they have no time for other relevant reading. We have failed to lead the students to read more and gather as much information in limited time to improve their reading efficiency. If any new word and grammar point, expansion of 
reading can help to review and consolidate knowledge and cover new information.

For those who just start fast-reading, they may come across such a problem as enhancement of reading speed affects accuracy of comprehension. Some students often say we have read too fast to understand the whole passage. Even though we have finished reading, we don't know what it is about. The training record has proved this phenomenon. In fact, it is just proved otherwise in practice in that given limited time those students are incompetent for fast-reading. They simply focus on reading speed to cover as much words as possible to broaden recognition space so that each word comes in sight, but the brain is left no room for evaluating or reacting. Another case is that in spite of sufficient time for evaluating each word in fast- reading, the thinking intelligence can't follow the pace. Therefore, this results in disconnection of sentence comprehension as well as the confusion upon the main idea of the text which is hindered by the grammar and details. Under such circumstances, Wang Shibin (2007)fast-reading is in conflict with comprehension since students just care about the "speed" rather that "accuracy". The competence of fast-reading is achieved through long-term steady training and cultivation. Students are required to find out their problems and figure out passable plans to cover various books to broaden their knowledge based on their personal study.

\section{TECHNIQUES TO IMPROVE FAST-READING}

To cope with those improper habits of reading, we will instruct students in scanning in sense groups, not in an individual word; in gaining the main idea of the text, not of a single sentence; to grasp the significance of literature directly from the brain, not from translation. Above all, the key to improving fast-reading is extensive reading. As following are some approaches and techniques to improve reading speed.

\section{A. $\quad$ Silent Reading}

Silent reading, the prerequisite for fast-reading, playing an important role in accelerating reading speed, since silent reading goes faster than the verbal reading, and the process of the latter coincide with the cooperative activities of four organs - eyes, brain, mouth and ears, through which symbols are first reflected to the eyes, then delivered to the brain; the brain orders the mouth to articulate, with the ears monitoring. In the contrast, silent reading is faster, for it involves eyes and brain only, without the performance of mouth and ears.

\section{B. Extensive Reading}

Extensive reading is reading books on vast fields in a fast way. It is essential to grasp the main idea and fix a clear reading target, say, 50 pages per day, 100 books can be fulfilled in a year.

\section{C. $\quad$ Timed Reading}

To take 5-10 minutes as a unit for reading and get fully attentive in the unit, for reading overtime easily leads to fatigue and distraction. To take down the starting and finishing time and work out reading speed. If you keep at it, timing is a good way to improve reading competence.

\section{Skimming}

Skimming is reading fast to get the gist of the text. To skim newspapers, magazines, novels or whatever you are interested in can make you broaden your horizon and enjoy the art of language. A qualified skimmer can read 3000-4000 words per minute.

\section{E. Scanning}

Scanning is glancing over the text at the highest speed for the details-the name of a person or a place, a particular date or event, etc. For instance, here is a calculator advertisement providing a variety of information of models, functions and prices of calculators. Supposing you would like to buy a calculator with reasonable price and function, you should first scan the prices, find out the affordable one, then compare between functions and at last choose the best one.

\section{F. Guessing the Meaning of a Certain Word from Context}

a. Encounter with new words in reading, you are able to guess the meaning of the word from the context.

(1) Guessing a certain word through the linking verb

Example: Sociology is the term used to describe the scientific study of human society.

Supposing sociology is a new word, the link verb to be has given its definition that is the science of human society.

(2) Guessing a certain word through the attributive clause

Example: This set of books is for children. The first book of the sequence, which is one of the most popular of children's stories, is a group of stories about the inhabitants of a village.

In the attributive clause, sequence is the synonym of series, so sequence here means a series of books.

(3) Guessing a certain word through its apposition

Example: The modern age of medicine began with the stethoscope, an instrument for listening to a patient's heartbeats and breathing. The apposition gives an accurate definition of stethoscope, a device to check the heartbeats.

b. Grasping the general meaning of a word 
The passage is likely to define to the key words, but for the unfamiliar ones. Sometimes, there is no need to get the exact meaning of such a word. It is passable to get its general meaning for reading and passage comprehension. To follow the rules to get the general meaning of such a word.

(1) Finding out the form of a word based on grammar. (noun, verb, adjective etc)

(2) Finding out the parallel term (usually of the same word class), they may be synonyms.

Example: Sally liked to concoct all sorts of stories, but her mother always knew when she is lying. "Concoct" here is used as a verb, and synonymous to "lie", for they both mean telling lies.

(3) Word building (compound, transfer, derivation) helps to define a word.

Observing the building of a word helps to identify the word and improve fast-reading. On one hand, readers don't need to refer to the dictionary and keep on reading; on the other hand, it will largely increase the reader's passive vocabulary. From the roots and affixes, readers can properly guess the word.

Example: Many cancers have been arrested with use of chemotherapy. Chemotherapy is the compounded by "chemical" and "therapy", which means the chemical treatment.

\section{G. Inference}

Generally, fast readers can infer the meaning of the whole sentence based on several words and it also applies to the paragraph. Therefore, an extensive reading can not only bring about a greater range of knowledge, a better understanding but also qualified inference capacity. It is this ability that contributes to catching the best-needed information. One approach of inference used in English reading is to learn to skip those insignificant words.

\section{H. Grasping the Key Sentence}

First of all, in order to improve reading speed, much more importance should be attached to the key sentence which serves as a bond in context. If the key sentence is within grasp, others problems will be easily solved. Catching the key sentence is to identifying the topic sentence, which is used to comprehend the main idea of the text. Usually, topic sentence comes in the first sentence of each paragraph and sometimes the last, and exceptionally in the middle. Generally, the main idea of each paragraph can be grasped quickly and accurately, by identifying the topic sentence, and then the central idea of the whole text is clear. Moreover, identifying and grasping the meaning of the topic sentence makes it easier to understand the author's thoughts, textual structure and logic between the lines. Consequently, therefore reading speed and accuracy of understanding are greatly promoted.

\section{CONCLUSIONS}

Apart from abovementioned, fast-reading boosts quick memorization. In fast-reading, the reader is highly concentrated. Continuous reading, an intensified activity strengthens and promotes fast memorization. To achieve the intensified memorization, here are three levels: first, cramming (which is necessary and indispensable level); second, the memory of association; third, the memory of comprehension. Say, reading modern narratives, what is requested to be crammed is the title, author, time, place, characters, names, celebrities and famous sayings, etc.; what should be memorized by association is the plot (causes for the event, development, the key plot, climax, outcome); what needs the memory of comprehension is the key sentence, key sentence of a paragraph, event nature, fate of the characters, author's attitude, change of personal subject, conception of word, meaning or gist of the article and so on. In short, fast-reading promotes comprehension, reading speed as well as instant memorization.

It's far from sufficient to learn the theory of fast-reading. To practice comes top important. Cultivation of reading competence is not achieved in a short time. It needs bilateral devotion from both teachers and students. Responsibility of English teachers does not only lie in imparting knowledge to students but also in instructing students in their capacity (Lou Heying, 2001). Thus in teaching, teachers are supposed to cultivate and inspire students in accordance with their personal levels with a clear target and help them expand their reading to get greater access to more English and American culture, broaden their horizon, grasp the adequate approaches of reading and endeavor to enhance their reading competence.

\section{REFERENCES}

[1] Fry. E. (1963). Teaching Faster Reading. Cambridge: Cambridge University Press.

[2] Gu, X. (1985). Strategies of reading. Tianjin: Nankai University Press

[3] Lou, H. (2001). College English teaching and research. Shanghai: Fudan University Press.

[4] Wang, S. (2007). Fast reading for English. Tianjin: Nankai University Press

Jun Xu was born in Binzhou, China in 1956. She majored in English Linguistics and Literature in the department of Foreign Studies, Liaocheng University, China in 1976-1979 and completed equivalent M.A. degree courses on English Linguistics and Literature in Shandong University, Jinan, China in 2002. Supported by Chinese State-funded students studying abroad Project, she was a full-time Visiting Scholar in School of English Study, Nottingham University, UK in 2002-2003.

She is currently an associate professor and the Director of the School of Foreign Languages, Dezhou University, Shandong, China. 
She has written "Study on analysis of Students' Speaking Error and PETS-Instruction of Students' Speaking Error Analysis in English Speaking Teaching", Vladivostock, Russia: Intelligent Potential of Advanced Education-Development of Russian Far East and Asia-Pacific Development, 2009; "Experiencing in Glamorous Language World", Yantai, China: Journal of Yantai Education Institute, 2004; "Backwash Effect on Current High School English Teaching in light of NMET", Shandong Enterprise Education, 2007; Translation works: The Cambridge Illustrated History of British Theatre', Shandong Pictorial Press. 2006. Her research interests include cross-cultural communication and English language teaching. 